\title{
Renal Heme Oxygenase-1 Induction with Hemin Augments Renal Hemodynamics, Renal Autoregulation, and Excretory Function
}

\author{
Fady T. Botros, ${ }^{1}$ Leszek Dobrowolski, ${ }^{1,2}$ and L. Gabriel Navar ${ }^{1}$ \\ ${ }^{1}$ Department of Physiology, Hypertension and Renal Center, Tulane University Health Sciences Center, 1430 Tulane Avenue, SL39, \\ New Orleans, LA 70112, USA \\ ${ }^{2}$ Laboratory of Renal and Body Fluid Physiology, Mossakowski Medical Research Centre, Polish Academy of Sciences, \\ A. Pawinskiego 5 Street, 02-106 Warsaw, Poland \\ Correspondence should be addressed to Fady T. Botros, fbotros@hotmail.com
}

Received 13 August 2011; Accepted 28 September 2011

Academic Editor: David E. Stec

Copyright ( $) 2012$ Fady T. Botros et al. This is an open access article distributed under the Creative Commons Attribution License, which permits unrestricted use, distribution, and reproduction in any medium, provided the original work is properly cited.

Heme oxygenases (HO-1; HO-2) catalyze conversion of heme to free iron, carbon monoxide, and biliverdin/bilirubin. To determine the effects of renal HO-1 induction on blood pressure and renal function, normal control rats $(n=7)$ and hemintreated rats $(n=6)$ were studied. Renal clearance studies were performed on anesthetized rats to assess renal function; renal blood flow (RBF) was measured using a transonic flow probe placed around the left renal artery. Hemin treatment significantly induced renal HO-1. Mean arterial pressure and heart rate were not different $(115 \pm 5 \mathrm{mmHg}$ versus $112 \pm 4 \mathrm{mmHg}$ and $331 \pm 16$ versus $346 \pm 10 \mathrm{bpm})$. However, $\mathrm{RBF}$ was significantly higher $(9.1 \pm 0.8$ versus $7.0 \pm 0.5 \mathrm{~mL} / \mathrm{min} / \mathrm{g}, P<0.05)$, and renal vascular resistance was significantly lower $(13.0 \pm 0.9$ versus $16.6 \pm 1.4[\mathrm{mmHg} /(\mathrm{mL} / \mathrm{min} / \mathrm{g})], P<0.05)$. Likewise, glomerular filtration rate was significantly elevated $(1.4 \pm 0.2$ versus $1.0 \pm 0.1 \mathrm{~mL} / \mathrm{min} / \mathrm{g}, P<0.05)$, and urine flow and sodium excretion were also higher $(18.9 \pm 3.9$ versus $8.2 \pm 1.0 \mu \mathrm{L} / \mathrm{min} / \mathrm{g}, P<0.05$ and $1.9 \pm 0.6$ versus $0.2 \pm 0.1 \mu \mathrm{mol} / \mathrm{min} / \mathrm{g}, P<0.05$, resp.). The plateau of the autoregulation relationship was elevated, and renal vascular responses to acute angiotensin II infusion were attenuated in hemin-treated rats reflecting the vasodilatory effect of HO-1 induction. We conclude that renal HO-1 induction augments renal function which may contribute to the antihypertensive effects of HO-1 induction observed in hypertension models.

\section{Introduction}

Heme metabolism is catalyzed by heme oxygenases (HO), which convert heme to carbon monoxide (CO), biliverdin, and free iron [1]. Two isoforms of $\mathrm{HO}$ are expressed in the kidney, HO-1 and HO-2 [2, 3]. The kidney has relatively low basal level of $\mathrm{HO}$ activity $[2,4]$ that is mainly derived from the constitutive HO-2 [5-7]. Renal HO-2 is localized to epithelial cells of the proximal tubule, thick ascending limb and distal tubule, connecting tubule, and principal cells of the collecting ducts [8]. Renal HO-1 is induced under certain pathological conditions and in response to several agents [3, 9-11]. The pattern of HO-1 expression in the kidney varies with different inducers utilized $[2,12]$. Acute treatment with hemin increases renal cortical dialysate CO concentration and causes diuresis and natriuresis [13]. Increases in renal perfusion pressure (RPP) induce renal CO production, and
HO inhibition prevents the pressure-dependent increase in $\mathrm{CO}$ and attenuates pressure natriuresis [14]. This suggests that induction of HO- 1 could modulate renal hemodynamics and renal excretory function.

$\mathrm{HO}$ inhibition during nitric oxide synthesis inhibition constricts afferent arterioles (Aff-Art) [15], and exogenous $\mathrm{CO}$ administration dilates renal Aff-Art from normal rats $[15,16]$. Furthermore, endogenously produced CO exerts a vasodilatory influence on the renal circulation, and inhibition of HO decreases renal blood flow (RBF) [17-21]. Bilirubin is also produced from heme metabolism by $\mathrm{HO}$ and biliverdin reductase and is an abundant endogenous antioxidant [22]. Bilirubin scavenges reactive oxygen species [23-25] and inhibits angiotensin II-mediated activation of NADPH oxidase $[26,27]$, effects that also potentially cause dilation of the renal microvasculature. Chronic treatment of angiotensin-II-infused hypertensive rats with bilirubin 
attenuates urinary protein excretion [28], and inhibition of bilirubin metabolism attenuates angiotensin II-dependent hypertension in mice [29]. Upregulation of renal HO-1 increases $\mathrm{CO}$ and biliverdin/bilirubin production, reduces NADPH oxidase-mediated oxidative stress [26], inhibits cortical 20-HETE synthesis [30], and inhibits thromboxane synthase [31]. Overexpression of HO-1 reduces the pressor responsiveness to angiotensin II [32], and inhibition of HO activity magnifies the renal vasoconstrictor effect of angiotensin II and enhances pressure-induced constriction of isolated pressurized renal interlobular arteries [20]. These results implicate HO-derived metabolites as important modulators of renal microcirculatory function. However, recent data indicate that blood pressure and RBF responses to increased angiotensin II or inhibition of nitric oxide are not significantly enhanced in HO-2 knockout mice [33].

This study was designed to examine the hypothesis that renal HO-1 induction augments renal hemodynamics and renal excretory function. To test this hypothesis, we performed renal clearance and renal hemodynamic studies on control and hemin-treated rats. Accordingly, the aims of this study were (1) to determine the effects of HO-1 induction on renal blood flow (RBF), glomerular filtration rate (GFR), and renal excretory function and (2) to determine the effects of HO-1 induction on RBF autoregulatory responses to changes in RPP and on the renal vasoconstrictor responses to angiotensin II.

\section{Methods}

2.1. Animal Treatment. All experimental protocols were approved by Tulane Institutional Animal Care and Use Committee. Male Sprague Dawley rats weighing 300-400 g were fed a normal rat diet (TD 90229, Harlan-Teklad) with free access to water. Two groups of rats were studied: (1) control rats and (2) Hemin-treated rats which received 4 i.p. injections of hemin for 4 consecutive days $(3 \mathrm{mg} / 100 \mathrm{~g}$ Bwt./ day) prior to the acute experiment.

2.2. Renal Function Studies. As described by Patterson et al. [34] and Wang et al. [35], on the day of acute experiment, rats were anesthetized with inactin (thiobutabarbital sodium, Sigma, Saint Louis, USA, $100 \mathrm{mg} / \mathrm{kg}$, i.p.) and placed on thermostatically controlled heated surgical table to maintain rectal temperature at $37^{\circ} \mathrm{C}$. A polyethylene tube was placed in the trachea and the animals were allowed to breathe air enriched with oxygen $\left(95 \% \mathrm{O}_{2} / 5 \% \mathrm{CO}_{2}\right)$. The left carotid artery was cannulated to allow continuous monitoring of systemic arterial blood pressure and heart rate. The left femoral vein was cannulated to allow infusion of solutions. The left kidney was exposed from a flank incision, gently freed, and placed in a plastic cup. For timed urine collections, a catheter was introduced into the ureter and passed to the pelvis. The renal artery was separated carefully from the renal vein which enabled placement of a noncannulating flow probe, $1 \mathrm{~mm}$ in the diameter, connected with a Transonic flowmeter (Transonic System Inc., Ithaca, NY, USA) for measurement of the total RBF. During surgery, an isotonic saline solution containing albumin $(6 \mathrm{~g} / \mathrm{dL}$ ) was infused at $1.2 \mathrm{~mL} / \mathrm{h}$ (for $300 \mathrm{~g}$ body weight). Following the surgical procedures, an isotonic saline solution containing 1\% albumin and 7.5\% polyfructosan (Inutest, Fresenius Kabi, Austria) was infused; initially a priming dose was infused at the rate of $1.6 \mathrm{~mL} / \mathrm{kg}$ for $5 \mathrm{~min}$ followed by a continuous infusion at $1.2 \mathrm{~mL} / \mathrm{h}$ and a stabilization period of about $1 \mathrm{~h}$ was allowed.

\subsubsection{Experimental Protocol}

Protocol 1. experiments were performed to determine the effects of HO-1 induction with hemin on renal hemodynamics and renal excretory function. After the stabilization period, at least six 15-minute collection periods were initiated during which measurements of mean arterial pressure (MAP), heart rate (HR), RBF, renal vascular resistance (RVR), GFR, urine flow (UV), and urinary sodium excretion $\left(\mathrm{U}_{\mathrm{Na}} \mathrm{V}\right)$ were averaged. Measurements for all collection periods were then averaged. The data from control and hemin-treated rats were compared.

Protocol 2. these experiments were done to determine the effects of HO- 1 induction with hemin on RBF autoregulatory responses. An aortic clamp was placed above the junction of the left renal artery to regulate RPP to the left kidney. The left femoral artery was cannulated, and the catheter was advanced up the aorta to measure RPP at the left kidney. A Transonic flow probe placed around the left renal artery was used to measure changes in RBF in response to decreases in RPP. After the stabilization period, RPP was decreased to 110, 100,90 , and $80 \mathrm{mmHg}$ and was maintained for 5 minutes at each level. MAP, HR, RBF, and RPP were averaged for each time period at different RPP.

Protocol 3. these experiments were done to determine the effects of HO-1 induction with hemin on renal vascular responses to angiotensin II. After the stabilization period, MAP and RBF were measured during i.v. infusion of vehicle followed by angiotensin II (Ang II 50, 100, and $200 \mathrm{ng} / \mathrm{kg} / \mathrm{min}$ ). Each infusion period lasted 30 minutes, and RBF responses were averaged during the last 20 minutes.

2.3. Analytical Procedures and Hemin Preparation. Urine volumes were determined gravimetrically. Blood samples were collected in heparinized tubes and centrifuged at $2500 \mathrm{~g}$ for $10 \mathrm{~min}$ at $4^{\circ} \mathrm{C}$ to separate the plasma, which was stored at $-20^{\circ} \mathrm{C}$. Plasma and urine sodium concentrations were measured by flame photometry. Polyfructosan concentrations in urine and plasma samples were measured by standard spectrophotometry. GFR was determined from the clearance of polyfructosan.

Hemin (Sigma-Aldrich, St. Louis, MO): $50 \mathrm{mg}$ hemin was dissolved in $1 \mathrm{~mL}$ of $0.1 \mathrm{M} \mathrm{NaOH}$; this solution was diluted using deionized water and $\mathrm{pH}$ was adjusted to 7.8 ; the final volume was adjusted to $5 \mathrm{~mL}$.

2.3.1. Tissue Preparation. Left kidneys were immediately collected and frozen at $-80^{\circ} \mathrm{C}$ until used for Western blot. 


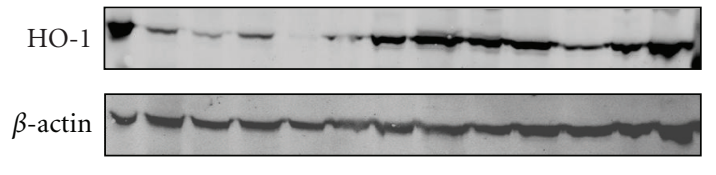

HO-1 protein expression

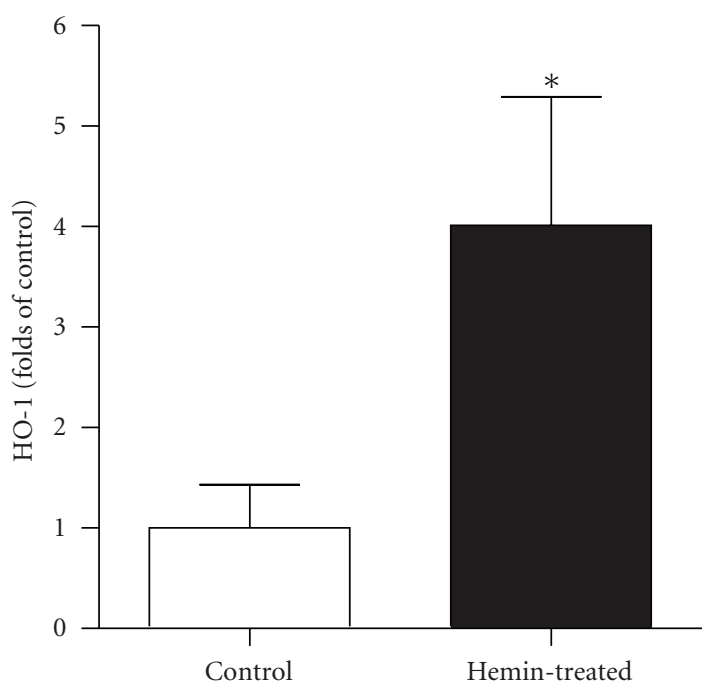

(a)

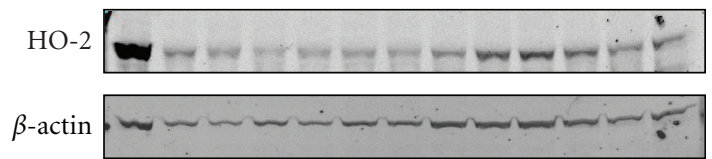

HO-2 protein expression

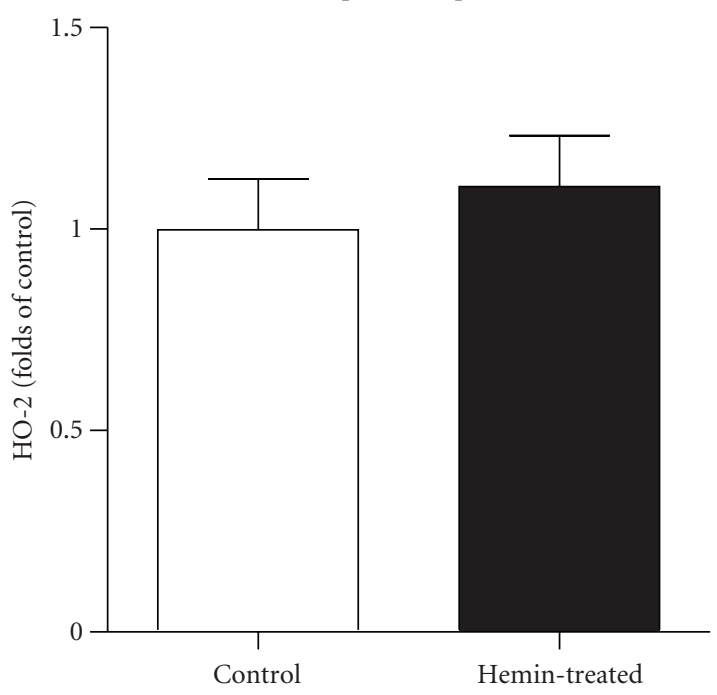

(b)

FIGURE 1: Western blot and densitometry analysis showing the effect of treatment with Hemin ( $3 \mathrm{mg} / 100 \mathrm{~g}$ body wt/day for 4 days) on renal HO- 1 and HO-2 protein expression $(n=6)$ compared to control rats $(n=6)$. Results are normalized by $\beta$-actin and expressed as folds of control and presented as mean $\pm \mathrm{SE}$ for each group, ${ }^{*} P<0.05$ versus Control.

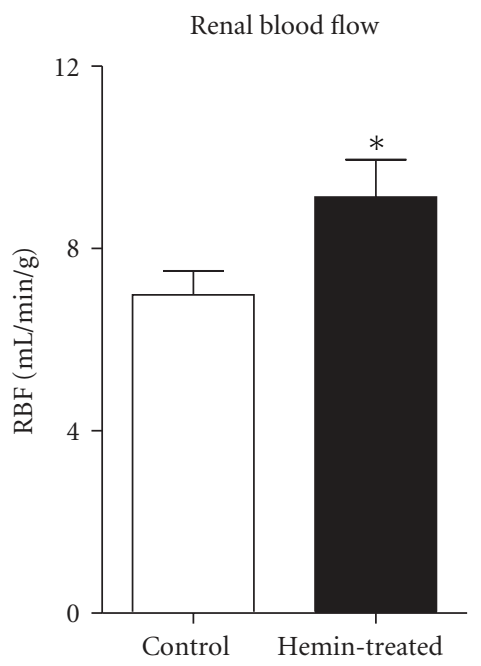

(a)

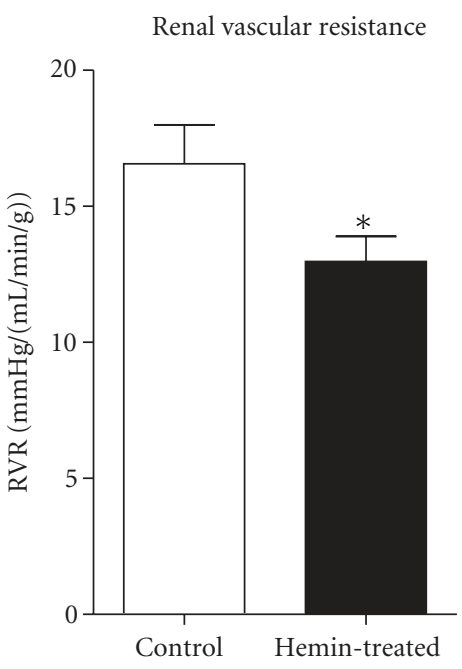

(b)

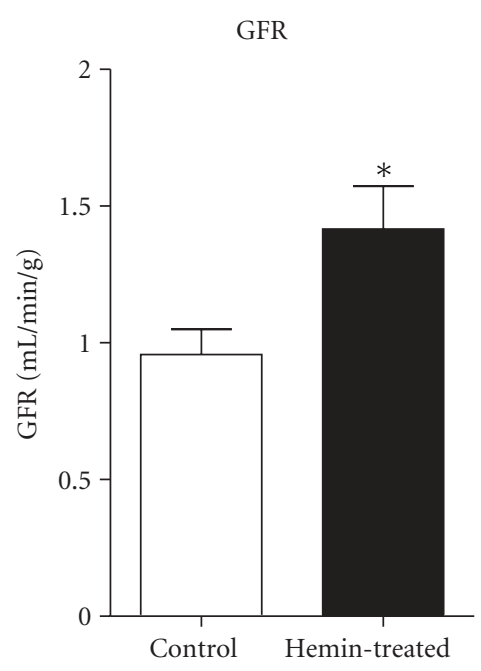

(c)

FIgURE 2: Renal blood flow (RBF), renal vascular resistance (RVR), and glomerular filtration rate $(\mathrm{GFR})$ in hemin-treated rats $(n=6)$ compared to control rats $(n=7)$. Results are expressed as mean \pm SE for each group, ${ }^{*} P<0.05$ versus Control.

Tissues were homogenized in buffer at $\mathrm{pH} 7.4$, containing $0.25 \mathrm{M}$ sucrose. The homogenates were centrifuged in an Eppendorf centrifuge at $10,000 \mathrm{~g}$ for $10 \mathrm{~min}$ at $4^{\circ} \mathrm{C}$ to remove unbroken cells and the supernatant was stored at $-80^{\circ} \mathrm{C}$. Protein concentration was determined according to the method of Bradford (BioRad, Hercules, CA) [36].
2.3.2. Western Blot Analysis. As previously described [30], cell-free homogenates $(10,000 \times \mathrm{g}$ supernatant $)$ of kidney preparations were separated by SDS/polyacrylamide gel electrophoresis and transferred to a hydrophobic polyvinylidene difluoride (PVDF) transfer membrane (Amersham-GE Biosciences, Piscataway, NJ). The membranes were incubated 
TABLE 1: Hemodynamics and renal excretory measurements in hemin-treated rats compared to control untreated rats.

\begin{tabular}{lcc}
\hline & Control $(n=7)$ & Hemin $(n=6)$ \\
\hline Mean arterial pressure, MAP $(\mathrm{mmHg})$ & $112 \pm 4$ & $115 \pm 5$ \\
Heart rate, HR $(\mathrm{bpm})$ & $346 \pm 10$ & $331 \pm 16$ \\
Glomerular filtration rate, GFR $(\mathrm{mL} / \mathrm{min} / \mathrm{g})$ & $1.0 \pm 0.1$ & $1.4 \pm 0.2^{*}$ \\
Renal blood flow, $\mathrm{RBF}(\mathrm{mL} / \mathrm{min} / \mathrm{gm})$ & $7.0 \pm 0.5$ & $9.1 \pm 0.8^{*}$ \\
Renal vascular resistance, $\mathrm{RVR}[\mathrm{mmHg} /(\mathrm{mL} / \mathrm{min} / \mathrm{g})]$ & $16.6 \pm 1.4$ & $13.0 \pm 0.9^{*}$ \\
Urine flow, $\mathrm{UV}(\mu \mathrm{L} / \mathrm{min} / \mathrm{g})$ & $8.2 \pm 1.0$ & $18.9 \pm 3.9^{*}$ \\
Sodium excretion, $\mathrm{U}_{\mathrm{Na}} \mathrm{V}(\mu \mathrm{mol} / \mathrm{min} / \mathrm{g})$ & $0.2 \pm 0.1$ & $1.9 \pm 0.6^{*}$ \\
\hline
\end{tabular}

${ }^{*} P<0.05$ versus control.

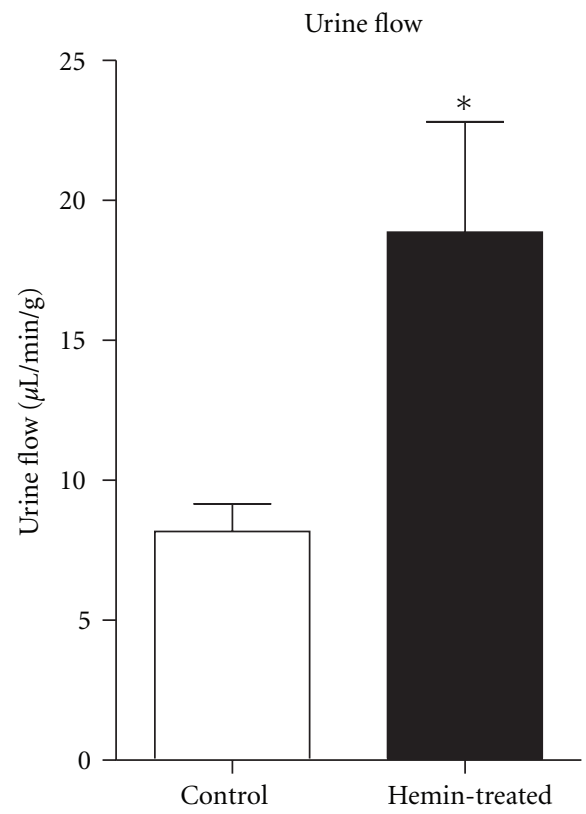

(a)

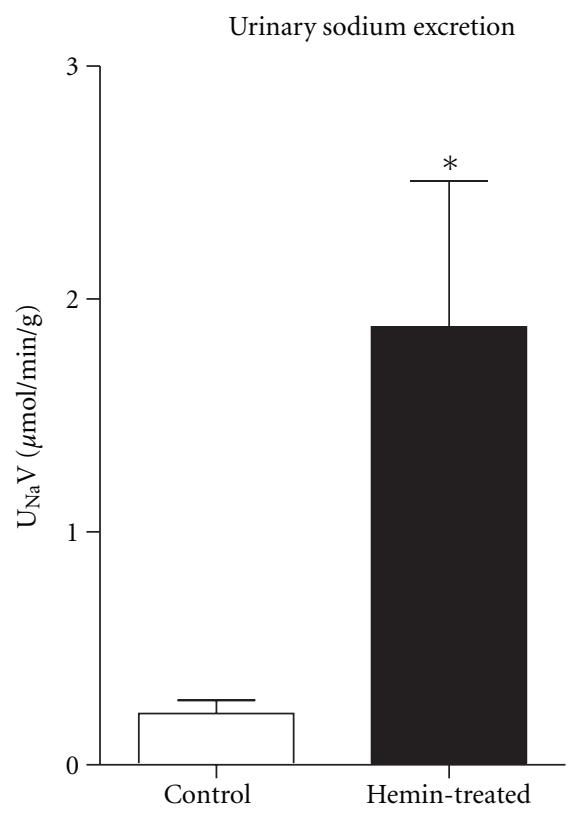

(b)

FIGURE 3: Urine flow (UV) and urinary sodium excretion $\left(\mathrm{U}_{\mathrm{Na}} \mathrm{V}\right)$ in hemin-treated rats $(n=6)$ compared to control rats $(n=7)$. Results are expressed as mean \pm SE for each group, ${ }^{*} P<0.05$ versus Control.

with Odyssey blocking reagent (LI-COR Biosciences, Lincoln, Nebraska) at $4^{\circ} \mathrm{C}$ overnight. The membranes were incubated for $1 \mathrm{hr}$ with one of the following antibodies: rabbit anti-rat HO-1 and HO-2 polyclonal antibodies ( $1: 1000$, Stressgen Biotechnologies Corp, Victoria, BC, Canada) or mouse anti- $\beta$-actin monoclonal antibody. The membranes were washed with phosphate buffered saline tween-20 (PBST) and subsequently probed with fluorescent tagged secondary antibodies at a dilution of $1: 15000$. The signal was detected using Odyssey fluorescent scanner.

2.4. Statistical Analysis. Results are presented as mean \pm SE for a number $(n)$ of experiments. Unpaired $t$-test was used to analyze differences in basal measurements, and HO-1 and HO-2 protein expression between the control and hemin-treated groups. Repeated measures one-way ANOVA followed by Bonferroni's multiple comparison test was used to analyze changes within the same group. Repeated measures two-way ANOVA followed by Bonferroni's multiple comparison test was used to analyze differences between groups. $P<0.05$ was considered statistically significant.

\section{Results}

3.1. HO-1 Protein Expression Is Induced in Kidneys from Hemin-Treated Rats. HO-1 protein expression significantly increased by $4.0 \pm 1.3$-fold in kidneys from hemin-treated rats compared to kidneys from normal control rats $(n=6$, $P<0.05$ ) (Figure 1). No differences in renal HO-2 expression between hemin-treated rats and normal control rats were detected (Figure 1).

3.2. Renal HO-1 Induction with Hemin Is Associated with Augmented Renal Hemodynamics and Excretory Function without 


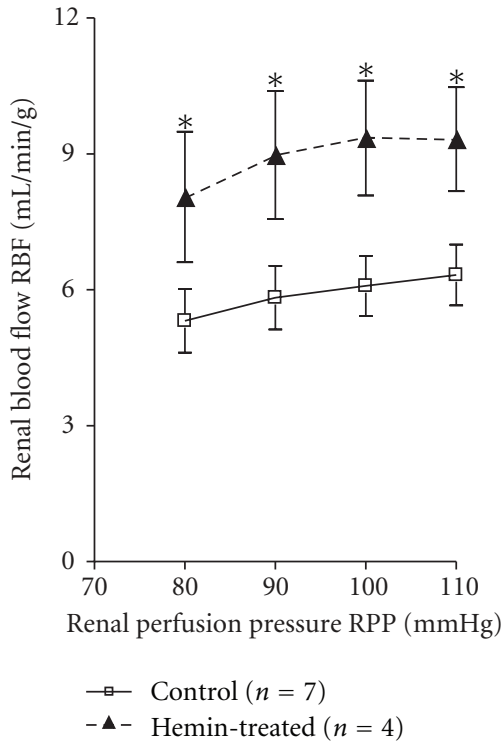

(a)

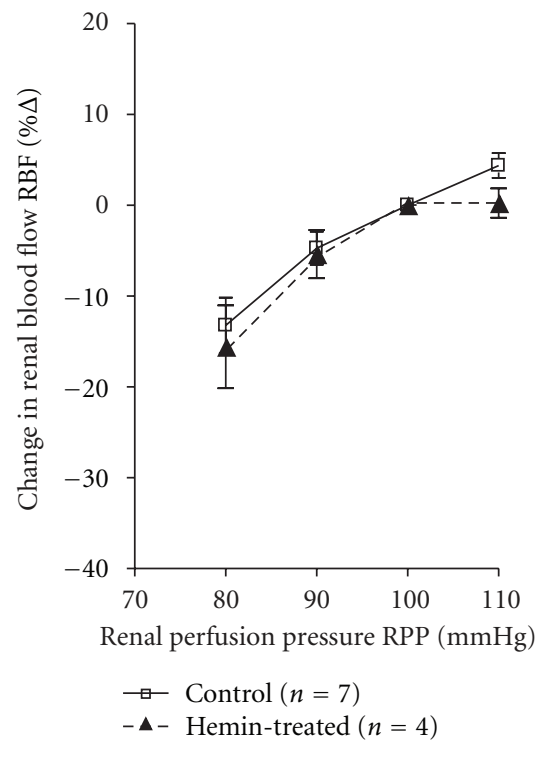

(b)

FIGURE 4: Renal blood flow (RBF) autoregulatory responses to changes in renal perfusion pressure $(\mathrm{RPP})$ in hemin-treated rats $(n=4)$ compared to control rats $(n=7)$. Results are expressed as mean \pm SE for each group, ${ }^{*} P<0.05$ versus Control.

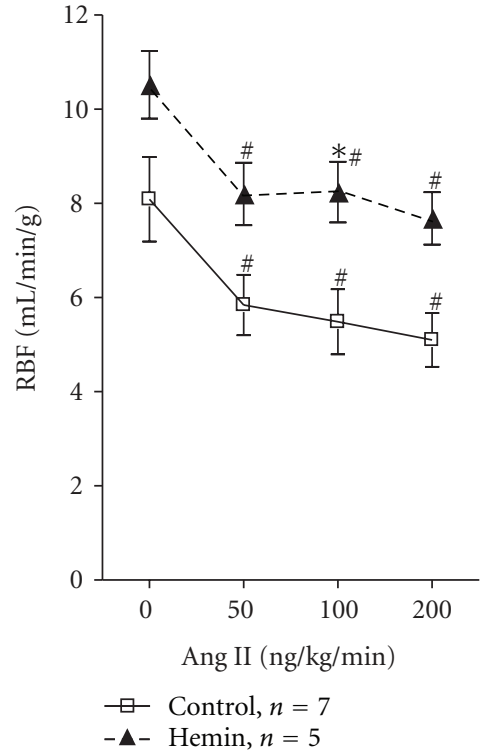

(a)

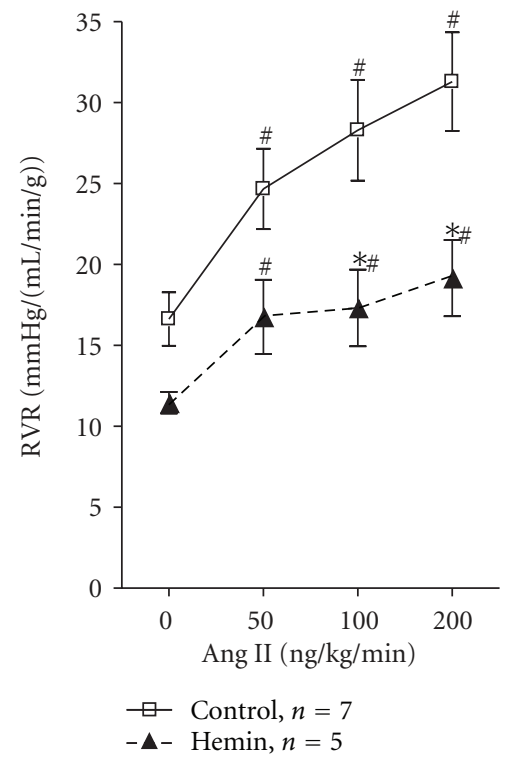

(b)

FIgURE 5: Changes in RBF and RVR in response to infusion of angiotensin II in hemin-treated rats $(n=5)$ compared to control rats $(n=7)$. Results are expressed as mean \pm SE for each group, ${ }^{*} P<0.05$ versus Control, ${ }^{\#} P<0.05$ versus baseline before angiotensin II infusion.

Alteration in Mean Arterial Pressure or Heart Rate. HR and MAP were not significantly different in hemin-treated rats compared to control rats (Table 1). While RBF and GFR were significantly higher, RVR was significantly lower in hemintreated rats (Table 1 and Figure 2). These data indicate that renal HO-1induction is associated with renal vasodilation in hemin-treated rats.

Hemin-treated rats also had increased urine flow and urinary sodium excretion $\left(\mathrm{U}_{\mathrm{Na}} \mathrm{V}\right)$ indicating that renal HO-1 induction is associated with augmented renal excretory function (Table 1 and Figure 3 ).

3.3. Hemin-Treatment Increases the RBF Autoregulatory Plateau in Response to Decreases in RPP. Figure 4(a) shows that RBF was significantly higher in hemin-treated rats compared to control rats at all measured RPP points indicating that the vasodilatory effect is maintained at different renal 
perfusion pressures. Figure 4(b) demonstrates that RBF autoregulatory responses to changes in RPP were not altered in hemin-treated rats indicating that renal autoregulatory responses are maintained with a tendency to show improved autoregulatory capability.

3.4. Renal HO-1 Induction with Hemin Is Associated with Attenuated Renal Vasoconstrictor Responses to Ang II and Maintained Pressor Responses. Basal MAP was not significantly different between control and hemin treated rats $(126.0 \pm 2.1 \mathrm{mmHg}, n=7$ versus $118.9 \pm 3.9 \mathrm{mmHg}, n=5)$. RBF was significantly higher in hemin treated rats compared to control rats $(10.5 \pm 0.7 \mathrm{~mL} / \mathrm{min} / \mathrm{g}, n=5$ versus $8.1 \pm$ $0.9 \mathrm{~mL} / \mathrm{min} / \mathrm{g}, n=7, P<0.05)$.

In response to angiotensin II infusion, MAP significantly increased to the same extent in both groups. In response to infusion with Ang II 50, 100, and $200 \mathrm{ng} / \mathrm{kg} / \mathrm{min}$, MAP increased from $126.0 \pm 2.1 \mathrm{mmHg}$ to $134.9 \pm 1.7,142.7 \pm$ 1.6 , and $150.7 \pm 2.2 \mathrm{mmHg}$ in the control group $(n=$ 7) and from $118.9 \pm 3.9$ to $131.4 \pm 7.2,136.9 \pm 9.3$, and $142.7 \pm 9.7 \mathrm{mmHg}$ in the hemin-treated rats $(n=5)$. RBF significantly decreased in response to infusion with Ang II 50, 100 , and $200 \mathrm{ng} / \mathrm{min} / \mathrm{kg}$ in both groups; however, RBF was significantly higher in the hemin-treated group compared to the control group $(P<0.0001)$. RBF during infusion with $200 \mathrm{ng} / \mathrm{min} / \mathrm{kg}$ Ang II was $7.7 \pm 0.6 \mathrm{~mL} / \mathrm{min} / \mathrm{g}$ in hemintreated group $(n=5)$ compared to $5.1 \pm 0.6 \mathrm{~mL} / \mathrm{min} / \mathrm{g}$ in control group $(n=7)$ (Figure 5$)$. The reduced responsiveness to Ang II infusion in the hemin treated group is shown by the attenuated increases in RVR with the Ang II infusions.

\section{Discussion}

HO-1 plays a major renoprotective role when induced under certain pathophysiological conditions $[4,9,17,19]$. Although several reports examined effects of acute activation or inhibition of $\mathrm{HO}$ via acute administration of the substrate hemin or HO inhibitors, the effects of chronic induction of HO- 1 on renal hemodynamics and renal excretory function have not been examined before. To determine the effects of $\mathrm{HO}-1$ on renal function, hemin was used to induce HO-1 expression [1]. Hemin increases $\mathrm{HO}$ activity via increasing substrate availability and also by transcriptional activation of hmox-1 gene [37]. Treating with HO-1 inducers causes differential induction of $\mathrm{HO}-1$ in the kidney; increased expression of HO-1 in different renal structures may exert different effects on renal function [38]. As expected, in our study chronic hemin administration increased HO-1 expression whereas it did not affect HO-2 expression.

In rats treated with hemin, MAP was not different compared to untreated rats; however, hemin-treated rats had significantly higher RBF and lower RVR. These results indicate that renal HO-1 induction exerts a renal vasodilatory effect. This is consistent with previously reported data that acute heme administration increases RBF, urine flow, and sodium excretion [13]. In addition, hemin-treated rats had significantly higher GFR compared to control rats indicating that the vasodilatory response is mediated through dilation of renal arterioles. These data are consistent with previous reports showing that acute inhibition of $\mathrm{HO}$ decreases $\mathrm{RBF}$ $[18,20]$ and infusion of CO increased RBF and GFR. In addition, CO causes vasodilation of afferent arterioles [15]. Interestingly, this renal vasodilatory response in hemintreated rats was associated with significantly higher urine flow (2-fold) and sodium excretion (10-fold) (Figure 3), indicating that $\mathrm{HO}-1$ induction exerts diuretic and natriuretic responses. This is consistent with previous data showing that acute heme administration causes natriuresis [13], while acute $\mathrm{HO}$ inhibition decreases urine flow and sodium excretion [39]. With chronic treatment, induction of HO-1 may be in different segments of the nephron and may be inhibiting other ion transporters; however, the effects of $\mathrm{HO}$ products on tubular transporters have not been well characterized. In addition, previous research shows that acute inhibition of $\mathrm{HO}$ with CrMP attenuates pressurenatriuresis, indicating that $\mathrm{HO}$ participates in the natriuretic response to increases in arterial pressure [14]. We speculate that the effects of chronic HO-1 induction on renal function are mediated directly via increases in $\mathrm{CO}$ and/or bilirubin production. However, indirect effects via regulation of other heme enzymes and/or renal transporters cannot be excluded.

To determine the effect of this vasodilatory response on renal autoregulatory capability, renal perfusion pressure was decreased using an aortic clamp and the corresponding RBF was recorded. Data presented in Figure 4 indicate that renal autoregulatory responses are maintained in hemin-treated rats albeit at higher RBF and changes in RBF in response to decreases in RPP were comparable in hemin-treated and control rats. This indicates that the renal vascular responses to changes in RPP are maintained; however, the plateau of the autoregulation relationship is elevated reflecting the vasodilatory effect of HO-1 induction. This may protect the kidney from excessive vasoconstriction during hypertension while limiting the deleterious effects of the increases in renal perfusion pressure, which could explain the renoprotective role of $\mathrm{HO}$ induction in different models of hypertension [38]. To examine this hypothesis, changes in RBF in response to acute infusion of angiotensin II were compared between hemin-treated and control untreated rat.

Angiotensin II infusion increased MAP to the same level in hemin-treated rats and control rats; however, renal vasoconstrictor responses were significantly attenuated in hemin-treated rats (Figure 5). This observation is consistent with previous data showing that the inhibition of $\mathrm{HO}$ with SnMP magnifies the renal vasoconstrictor effect of angiotensin II [20]. Although RBF significantly decreased in both control and hemin-treated rats, the increase in RVR in response to angiotensin II was significantly greater in control rats than in hemin-treated rats (Figure 5). This finding is of significant importance because induction of HO- 1 by heme administration to angiotensin-II-infused hypertensive rats increases creatinine clearance and decreases proteinuria [17], indicating a renoprotective effect of $\mathrm{HO}$ 1 during angiotensin II hypertension. In addition, chronic hemin infusions normalize blood pressure in spontaneously 
hypertensive rats [40] and induction of $\mathrm{HO}-1$ prevents the blood pressure increase in angiotensin-II-infused mice [41].

In summary, the present study demonstrates that pharmacological renal HO-1 induction increases RBF, GFR, urine flow, and sodium excretion; these effects are conducive to renoprotection. Renal autoregulatory responses are maintained but operate at a higher RBF during $\mathrm{HO}-1$ induction. Finally, renal HO-1 induction with hemin significantly attenuates renal vasoconstrictor responses to angiotensin II. Under several pathophysiological conditions, HO1 is induced in the kidney [9]; renal HO-1 induction under these circumstances might play a renoprotective role by attenuating excessive renal vasoconstrictor responses.

\section{Disclosure}

Fady T. Botros is a Clinical Research Scientist at the Lilly Research Laboratories, Eli Lilly and Company, Indianapolis, IN, USA.

\section{Acknowledgments}

Research support was provided by NHLBI Grant HL 18426 and a COBRE Grant P20 RR 017659 from the Institutional Award Program of the National Center for Research Resources. The Western blot analysis was performed in the Molecular and Analytical core of the CoBRE.

\section{References}

[1] R. Tenhunen, H. S. Marver, and R. Schmid, "The enzymatic conversion of heme to bilirubin by microsomal heme oxygenase," Proceedings of the National Academy of Sciences of the United States of America, vol. 61, no. 2, pp. 748-755, 1968.

[2] J. L. Da Silva, B. A. Zand, L. M. Yang, H. E. Sabaawy, E. Lianos, and N. G. Abraham, "Heme oxygenase isoform-specific expression and distribution in the rat kidney," Kidney International, vol. 59, no. 4, pp. 1448-1457, 2001.

[3] N. Hill-Kapturczak, S. H. Chang, and A. Agarwal, "Heme oxygenase and the kidney," DNA and Cell Biology, vol. 21, no. 4, pp. 307-321, 2002.

[4] F. T. Botros, M. L. Schwartzman, C. T. Stier Jr., A. I. Goodman, and N. G. Abraham, "Increase in heme oxygenase-1 levels ameliorates renovascular hypertension," Kidney International, vol. 68, no. 6, pp. 2745-2755, 2005.

[5] N. G. Abraham, G. S. Drummond, J. D. Lutton, and A. Kappas, "The biological significance and physiological role of heme oxygenase," Cellular Physiology and Biochemistry, vol. 6, no. 3, pp. 129-168, 1996.

[6] M. D. Maines, "The heme oxygenase system: a regulator of second messenger gases," Annual Review of Pharmacology and Toxicology, vol. 37, pp. 517-554, 1997.

[7] M. D. Maines, G. M. Trakshel, and R. K. Kutty, "Characterization of two constitutive forms of rat liver microsomal heme oxygenase. Only one molecular species of the enzyme is inducible," Journal of Biological Chemistry, vol. 261, no. 1, pp. 411-419, 1986.

[8] Y. Hu, N. Ma, M. Yang, and R. Semba, "Expression and distribution of heme oxygenase- 2 mRNA and protein in rat kidney,"
Journal of Histochemistry and Cytochemistry, vol. 46, no. 2, pp. 249-256, 1998.

[9] K. A. Nath, "Heme oxygenase-1: a provenance for cytoprotective pathways in the kidney and other tissues," Kidney International, vol. 70, no. 3, pp. 432-443, 2006.

[10] M. Shepard, P. Dhulipala, S. Kabaria, N. G. Abraham, and E. A. Lianos, "Heme oxygenase-1 localization in the rat nephron," Nephron, vol. 92, no. 3, pp. 660-664, 2002.

[11] E. M. Sikorski, T. Hock, N. Hill-Kapturczak, and A. Agarwal, "The story so far: molecular regulation of the heme oxygenase1 gene in renal injury," American Journal of Physiology, vol. 286, no. 3, pp. F425-F441, 2004.

[12] N. G. Abraham, F. T. Botros, R. Rezzani, L. Rodella, R. Bianchi, and A. I. Goodman, "Differential effect of cobalt protoporphyrin on distributions of heme oxygenase in renal structure and on blood pressure in SHR," Cellular and Molecular Biology, vol. 48, no. 8, pp. 895-902, 2002.

[13] F. Rodriguez, R. Kemp, M. Balazy, and A. Nasjletti, "Effects of exogenous heme on renal function: role of heme oxygenase and cyclooxygenase," Hypertension, vol. 42, no. 4, pp. 680-684, 2003.

[14] N. Li, F. Yi, E. A. Dos Santos, D. K. Donley, and P. L. Li, "Role of renal medullary heme oxygenase in the regulation of pressure natriuresis and arterial blood pressure," Hypertension, vol. 49, no. 1, pp. 148-154, 2007.

[15] F. T. Botros and L. G. Navar, "Interaction between endogenously produced carbon monoxide and nitric oxide in regulation of renal afferent arterioles," American Journal of Physiology, vol. 291, no. 6, pp. H2772-H2778, 2006.

[16] C. Thorup, C. L. Jones, S. S. Gross, L. C. Moore, and M. S. Goligorsky, "Carbon monoxide induces vasodilation and nitric oxide release but suppresses endothelial NOS," American Journal of Physiology, vol. 277, no. 6, pp. F882-F889, 1999.

[17] T. Aizawa, N. Ishizaka, J. I. Taguchi et al., "Heme oxygenase-1 is upregulated in the kidney of angiotensin II-induced hypertensive rats: possible role in renoprotection," Hypertension, vol. 35, no. 3, pp. 800-806, 2000.

[18] B. Arregui, B. López, M. G. Salom, F. Valero, C. Navarro, and F. J. Fenoy, "Acute renal hemodynamic effects of dimanganese decacarbonyl and cobalt protoporphyrin," Kidney International, vol. 65, no. 2, pp. 564-574, 2004.

[19] T. L. O’Donaughy and B. R. Walker, "Renal vasodilatory influence of endogenous carbon monoxide in chronically hypoxic rats," American Journal of Physiology, vol. 279, no. 6, pp. H2908-H2915, 2000.

[20] F. Rodriguez, F. Zhang, S. Dinocca, and A. Nasjletti, "Nitric oxide synthesis influences the renal vascular response to heme oxygenase inhibition," American Journal of Physiology, vol. 284, no. 6, pp. F1255-F1262, 2003.

[21] A. P. Zou, H. Billington, N. Su, and A. W. Cowley, "Expression and actions of heme oxygenase in the renal medulla of rats," Hypertension, vol. 35, no. 1, pp. 342-347, 2000.

[22] R. Stocker, Y. Yamamoto, and A. F. McDonagh, "Bilirubin is an antioxidant of possible physiological importance," Science, vol. 235, no. 4792, pp. 1043-1046, 1987.

[23] J. E. Clark, R. Foresti, C. J. Green, and R. Motterlini, "Dynamics of haem oxygenase- 1 expression and bilirubin production in cellular protection against oxidative stress," Biochemical Journal, vol. 348, no. 3, pp. 615-619, 2000.

[24] S. Doré, M. Takahashi, C. D. Ferris, L. D. Hester, D. Guastella, and S. H. Snyder, "Bilirubin, formed by activation of heme oxygenase-2, protects neurons against oxidative stress injury," Proceedings of the National Academy of Sciences of the United States of America, vol. 96, no. 5, pp. 2445-2450, 1999. 
[25] J. Neuzil and R. Stocker, "Free and albumin-bound bilirubin are efficient co-antioxidants for $\alpha$ - tocopherol, inhibiting plasma and low density lipoprotein lipid peroxidation," Journal of Biological Chemistry, vol. 269, no. 24, pp. 16712-16719, 1994.

[26] S. R. Datla, G. J. Dusting, T. A. Mori, C. J. Taylor, K. D. Croft, and F. Jiang, "Induction of heme oxygenase-1 in vivo suppresses NADPH oxidase-derived oxidative stress," Hypertension, vol. 50, no. 4, pp. 636-642, 2007.

[27] A. Pflueger, A. J. Croatt, T. E. Peterson et al., "The hyperbilirubinemic Gunn rat is resistant to the pressor effects of angiotensin II," American Journal of Physiology, vol. 288, no. 3, pp. F552-F558, 2005.

[28] R. M. LeBlanc, L. G. Navar, and F. T. Botros, "Bilirubin exerts renoprotective effects in angiotensin II-hypertension," American Journal of the Medical Sciences, vol. 340, no. 2, pp. 144-146, 2010.

[29] T. Vera, J. P. Granger, and D. E. Stec, "Inhibition of bilirubin metabolism induces moderate hyperbilirubinemia and attenuates ANG II-dependent hypertension in mice," American Journal of Physiology, vol. 297, no. 3, pp. R738-R743, 2009.

[30] F. T. Botros, M. Laniado-Schwartzman, and N. G. Abraham, "Regulation of cyclooxygenase- and cytochrome P450-derived eicosanoids by heme oxygenase in the rat kidney," Hypertension, vol. 39, no. 2, pp. 639-644, 2002.

[31] W. C. Sessa, N. G. Abraham, B. Escalante, and M. L. Schwartzman, "Manipulation of cytochrome P-450 dependent renal thromboxane synthase activity in spontaneously hypertensive rats," Journal of Hypertension, vol. 7, no. 1, pp. 37-42, 1989.

[32] L. Yang, S. Quan, A. Nasjletti, M. Laniado-Schwartzman, and N. G. Abraham, "Heme oxygenase-1 gene expression modulates angiotensin II-induced increase in blood pressure," Hypertension, vol. 43, no. 6, pp. 1221-1226, 2004.

[33] D. E. Stec, T. Vera, M. V. Storm, G. R. McLemore, and M. J. Ryan, "Blood pressure and renal blow flow responses in heme oxygenase-2 knockout mice," American Journal of Physiology, vol. 297, no. 6, pp. R1822-R1828, 2009.

[34] M. E. Patterson, C. R. Mouton, J. J. Mullins, and K. D. Mitchell, "Interactive effects of superoxide anion and nitric oxide on blood pressure and renal hemodynamics in transgenic rats with inducible malignant hypertension," American Journal of Physiology, vol. 289, no. 4, pp. F754-F759, 2005.

[35] C. T. Wang, L. G. Navar, and K. D. Mitchell, "Proximal tubular fluid angiotensin II levels in angiotensin II-induced hypertensive rats," Journal of Hypertension, vol. 21, no. 2, pp. 353360, 2003.

[36] M. M. Bradford, "A rapid and sensitive method for the quantitation of microgram quantities of protein utilizing the principle of protein dye binding," Analytical Biochemistry, vol. 72, no. 1-2, pp. 248-254, 1976.

[37] M. J. Tracz, J. Alam, and K. A. Nath, "Physiology and pathophysiology of heme: implications for kidney disease," Journal of the American Society of Nephrology, vol. 18, no. 2, pp. 414420, 2007.

[38] F. T. Botros and L. G. Navar, "Heme oxygenase in regulation of renal function and blood pressure," Current Hypertension Reviews, vol. 5, no. 1, pp. 13-23, 2009.

[39] K. E. Jackson, D. W. Jackson, S. Quadri, M. J. Reitzell, and L. G. Navar, "Inhibition of heme oxygenase augments tubular sodium reabsorption," American Journal of Physiology, vol. 300, no. 4, pp. F941-F946, 2011.

[40] R. Wang, R. Shamloul, X. Wang, Q. Meng, and L. Wu, "Sustained normalization of high blood pressure in spontaneously hypertensive rats by implanted hemin pump," Hypertension, vol. 48, no. 4, pp. 685-692, 2006.

[41] T. Vera, S. Kelsen, L. L. Yanes, J. F. Reckelhoff, and D. E. Stec, "HO-1 induction lowers blood pressure and superoxide production in the renal medulla of angiotensin II hypertensive mice," American Journal of Physiology, vol. 292, no. 4, pp. R1472-R1478, 2007. 


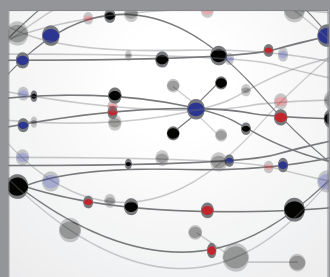

The Scientific World Journal
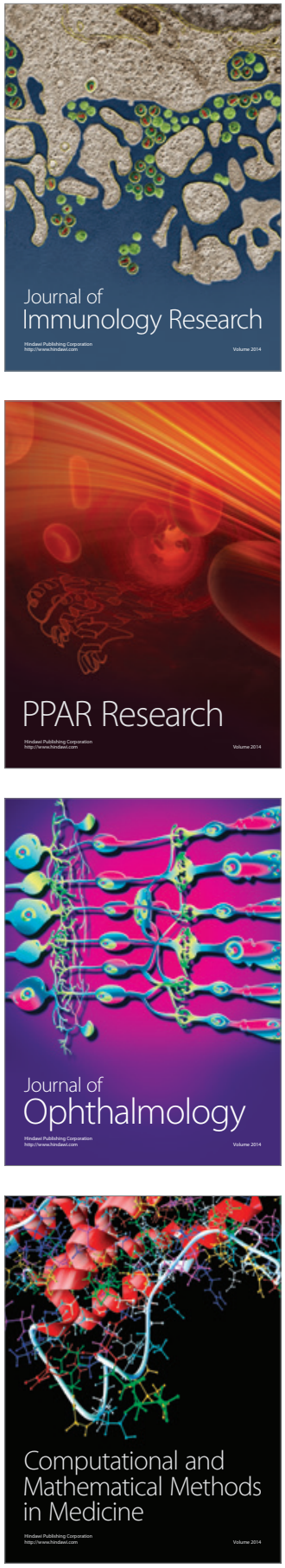

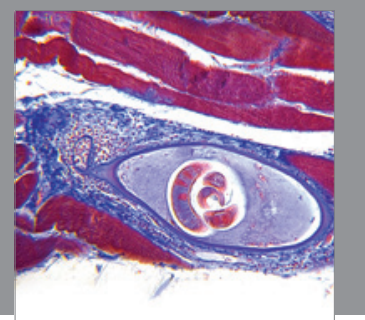

Gastroenterology

Research and Practice
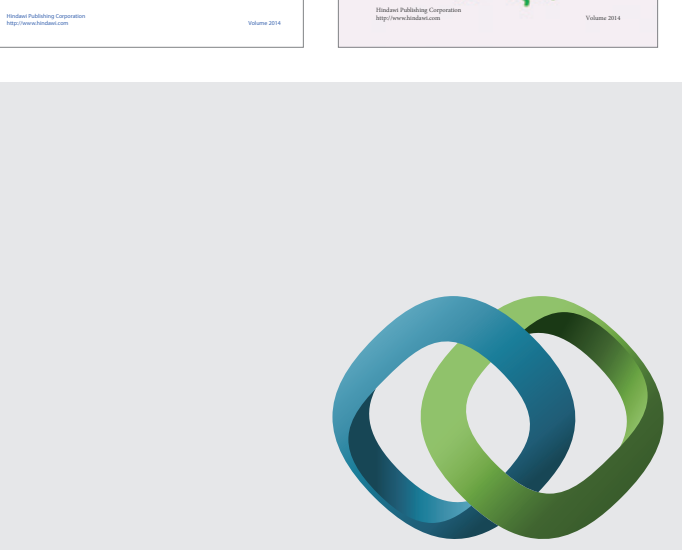

\section{Hindawi}

Submit your manuscripts at

http://www.hindawi.com
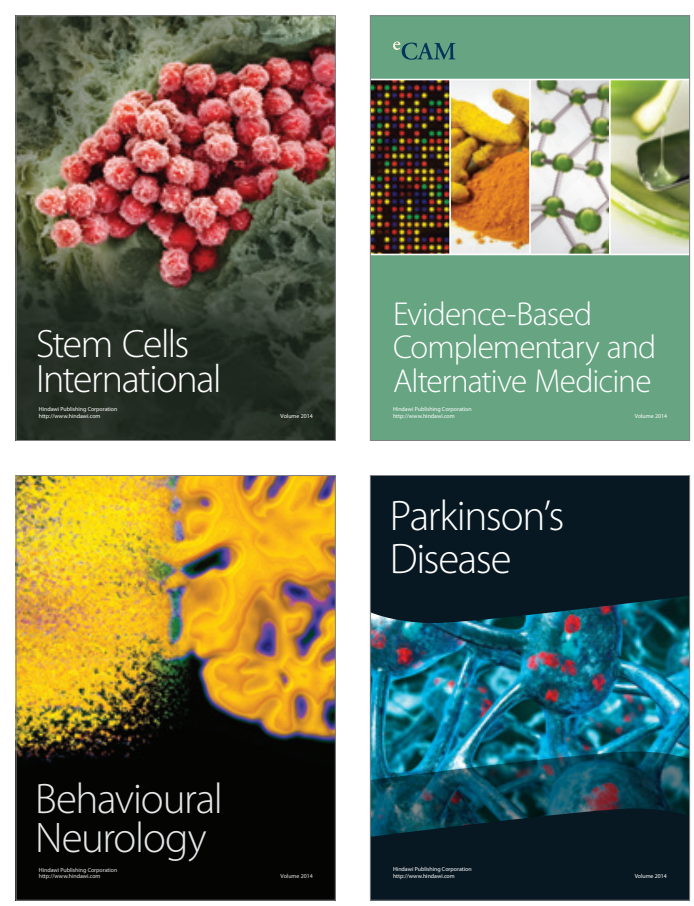

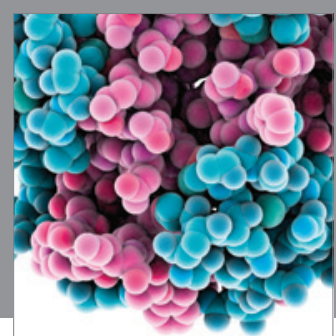

Journal of
Diabetes Research

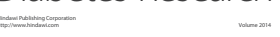

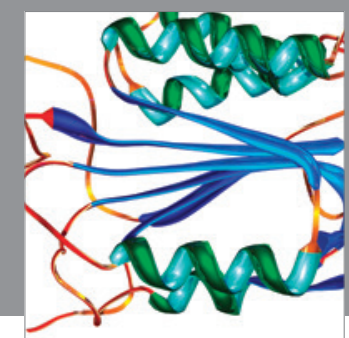

Disease Markers
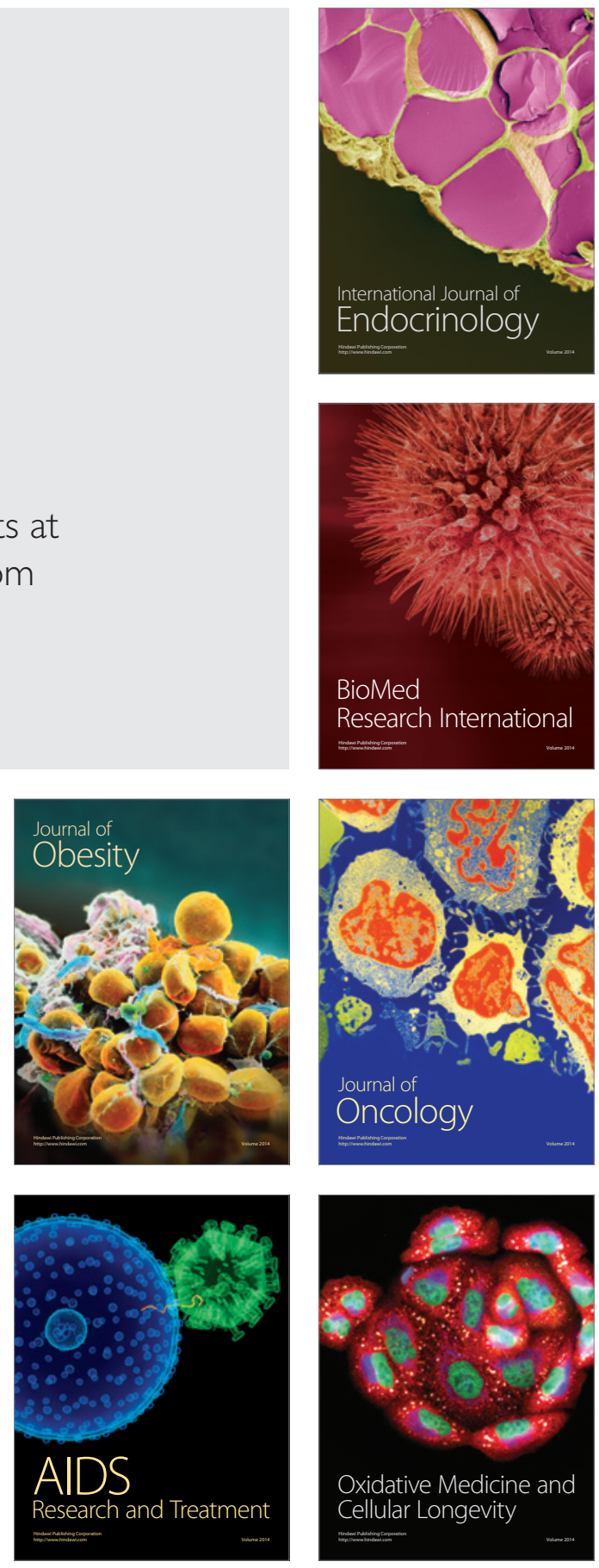